\title{
Patients' perspectives of prehabilitation as an extension of Enhanced Recovery After Surgery protocols
}

\author{
Chelsia Gillis, PhD, RD* \\ Marlyn Gill, MSW* \\ Leah Gramlich, MD \\ S. Nicole Culos-Reed, PhD \\ Gregg Nelson, MD, PhD \\ Olle Ljungqvist, MD, PhD \\ Franco Carli, MD, MPhil \\ Tanis Fenton, RD, PhD
}

*These authors contributed equally to this work.

Accepted Nov. 30, 2021

Correspondence to:

C. Gillis

Cumming School of Medicine

Department of Community Health

Sciences

University of Calgary

Calgary AB T2N $4 Z 6$

chelsia.gillis@ucalgary.ca

Cite as: Can J Surg 2021 November 2; 64(6). doi: 10.1503/cjs.014420

\begin{abstract}
Background: Enhanced Recovery After Surgery (ERAS) and prehabilitation programs are evidence-based and patient-focused, yet meaningful patient input could further enhance these interventions to produce superior patient outcomes and patient experiences. We conducted a qualitative study with patients who had undergone colorectal surgery under ERAS care to determine how they prepared for surgery, their views on prehabilitation and how prehabilitation could be delivered to best meet patient needs.
\end{abstract}

Methods: We conducted semistructured interviews with adult patients who had undergone colorectal surgery under ERAS care within 3 months after surgery. Patients were enrolled between April 2018 and June 2019 through purposive sampling from 1 hospital in Alberta. The interview transcripts were analyzed independently by a researcher and a trained patient-researcher using inductive thematic analysis.

Results: Twenty patients were interviewed. Three main themes were identified. First, waiting for surgery: patients described fear, anxiety, isolation and deterioration of their mental and physical states as they waited passively for surgery. Second, preparing would have been better than just waiting: patients perceived that a prehabilitation program could prepare them for their operation if it addressed their emotional and physical needs, provided personalized support, offered home strategies, involved family and included surgical expectations (both what to expect and what is expected of them). Third, partnering with patients: preoperative preparation should occur on a continuum that meets patients where they are at and in a partnership that respects patients' expertise and desired level of engagement.

Conclusion: We identified several patient priorities for the preoperative period. Integrating these priorities within ERAS and prehabilitative programs could improve patient satisfaction, experiences and outcomes. Actively engaging patients in their care might alleviate some of the anxiety and fear associated with waiting passively for surgery.

Contexte : Les protocoles de récupération optimisée après une chirurgie (ERAS, pour Enhanced Recovery After Surgery) et les programmes de préadaptation se fondent sur des données probantes et sont centrés sur les patients et pourtant, une plus grande contribution de ces derniers permettrait d'améliorer ces interventions et donneraient lieu à des résultats et des expériences plus satisfaisants pour les patients. Nous avons procédé à une étude qualitative auprès de patients ayant subi une chirurgie colorectale avec protocole ERAS afin de savoir comment ils se sont préparés à la chirurgie, quel est leur point de vue sur la préadaptation et en quoi cette dernière pourrait mieux répondre à leurs besoins.

Méthodes : Nous avons réalisé des entrevues semi-structurées auprès de patients adultes ayant subi une chirurgie colorectale avec protocole ERAS dans les 3 mois suivant leur chirurgie. Les patients ont été inscrits dans un hôpital albertain entre avril 2018 et juin 2019 par le biais d'un échantillonnage dirigé. Les transcriptions des entrevues ont fait l'objet d'une analyse thématique inductive indépendante par une chercheuse et une patientechercheuse dûment formée.

Résultats : Vingt patients ont été interrogés. Trois grands thèmes ont été dégagés : 1) en attente de la chirurgie (les patients ont fait état de peur, d'anxiété, d'un sentiment d'isolement et d'une détérioration de leur état de santé mentale et physique durant l'attente passive de la chirurgie); 2) une préparation leur a semblé préférable à une simple attente (les patients ont senti qu'un programme de préadaptation les aiderait à se préparer à leur chirurgie s'il tenait compte de leurs besoins émotionnels et physiques, s'il fournissait un soutien personnalisé, des stratégies de soutien à domicile, s'il impliquait les familles et incluait une discussion sur les attentes vis-à-vis de la chirurgie); et 3) partenariat avec les 
patients (la préparation devrait se dérouler selon un continuum adapté à la situation de chaque patient sous la forme d'un partenariat qui respecte son expertise et son niveau d'engagement).

Conclusion : Nous avons identifié plusieurs priorités pour les patients durant l'étape préopératoire. Intégrer ces priorités dans les protocoles ERAS et les programmes de préadaptation pourrait améliorer la satisfaction, les expériences et les résultats chez les patients. Faire participer activement les patients à leurs soins pourrait contribuer à soulager une part de l'anxiété et de la peur associées à l'attente passive de la chirurgie.

$\mathbf{T}$ he Enhanced Recovery After Surgery (ERAS) program for colorectal surgery involves the implementation and evaluation of more than 20 multimodal elements of perioperative care. ${ }^{1}$ Collectively, these elements standardize surgical practice, attenuate surgical stress and support intermediate recovery, including earlier discharge from hospital. ${ }^{2-4}$

Complementary to ERAS, prehabilitation programs aim to work with patients to optimize their physical and mental well-being before surgery, enhancing metabolic capacity to withstand surgical stress and facilitating longerterm recovery, including return of presurgery strength and function. ${ }^{5}$ Prehabilitation programs may be unimodal ${ }^{6}$ (e.g., exercise only) or multimodal ${ }^{7}$ (e.g., exercise, nutrition and anxiety reduction), and are implemented during the natural waiting period for surgery. Prehabilitation programs for colorectal surgery are typically initiated 4 weeks before surgery and may include personalized counselling to optimize cardiorespiratory, nutritional and mental wellbeing. ${ }^{7}$ The elements of prehabilitation typically are not static; rather, they are dynamic and responsive to personalized patient risk factors, abilities and willingness to participate. ${ }^{5}$ The goal of most prehabilitation programs is to promote surgical resiliency, agency and self-efficacy. ${ }^{8}$

Although both ERAS and prehabilitation programs are evidence-based and patient-oriented, there is a dearth of published evidence examining patient input to enhance such programs. Meaningful patient input could enhance these interventions to produce superior patient outcomes and experiences. In fact, integrating patient engagement research within the health care system is a recognized strategy of the Canadian Institutes of Health Research to improve health outcomes by $2025 .{ }^{9}$

The traditional role of patients and their families has long been as the recipients of care that is "done to" them and, on occasion, as participants in clinical studies. In contrast, under the umbrella of patient engagement, patients are not passive recipients of health care but, rather, assume shared responsibility for their health and health care decisions, and in the improvement of both health care research and services. ${ }^{10}$ Involving patients in health care decisionmaking has the potential to reduce costly mismatches between research and patient needs, improve the quality and uptake of interventions, and enhance patient satisfaction and outcomes. ${ }^{11,12}$ In addition, researchers report enhanced enrolment and retention of study participants when patients are engaged in their care, ${ }^{13}$ thus facilitating the achievement of important study objectives that enhance internal validity by avoiding selection and attrition bias.

A systematic review of 11 qualitative studies on patients' experiences of ERAS highlighted several patient-oriented issues that could be addressed to foster improvement. ${ }^{14}$ Specifically, patients expressed a need to clearly understand the rationale for each ERAS element in order to feel convinced and motivated to make an effort to adhere to the elements ('It's all very well giving me the dos and don'ts, but I want to know why you do and why you don't do this"). The authors also concluded that patients were highly motivated to be active participants in their own recovery. These findings resonate with our previous qualitative patient-led work with patients under ERAS care after colorectal surgery, in which participatory analysis of patient interviews and focus groups produced the following overarching concept: "Invite me into ERAS, from diagnosis to recovery, so that I can take responsibility for my own health."15 Building surgical care programs with patient input has great potential to enhance patient experience and improve outcomes.

The objectives of the present study were to describe 1) how patients who had undergone colorectal surgery under ERAS care prepared for surgery; 2) patients' views on prehabilitation, including whether they felt that a prehabilitation program would be an acceptable addition to future surgical care; and 3) how prehabilitation could be delivered to best meet patient needs.

\section{Methods}

\section{Setting and design}

We conducted a qualitative study at a single hospital providing ERAS care for colorectal surgery.

\section{Enhanced Recovery After Surgery}

Given that the context of our surgical setting would influence patient responses, we provide details of our ERAS program here. At our institution, preoperative ERAS education is offered to all patients undergoing colorectal surgery as an optional, single-session group class cotaught by an ERAS-trained nurse and a dietitian. The nurse explains the ERAS elements and what is expected of patients, and describes the surgical experience so that patients are better 
prepared for their operation. The dietitian explains the postoperative diet, encourages the use of oral nutrition supplements and lets patients know she is available to them on request while they are in hospital.

Preoperative optimization with prehabilitation was not part of ERAS care at our institution at the time of the study.

\section{Recruitment}

Patient participants were enrolled between April 2018 and June 2019 through purposive sampling from 1 hospital in Alberta with the use of the ERASAlberta Implementation Program for colorectal surgery. ${ }^{3}$ Participants had to be older than 18 years of age, speak English well enough to participate in an interview, have had primary colorectal surgery under ERAS care within the preceding 3 months and have not participated in a prehabilitation program previously. Patients who met the inclusion criteria were approached by hospital staff during their hospital stay for surgery to obtain verbal permission for C.G. to explain study details. We aimed to select a representative sample that included all bowel diseases and ERAS-compliant and non-ERAS-compliant patients, as well as patients with uneventful and difficult surgical recoveries.

C.G. obtained informed consent and scheduled the interviews. The researchers had no prior relationship with any of the study participants. Ethics approval for the study was obtained from the University of Calgary Conjoint Research Ethics Board (REB17-2138).

\section{Data collection}

Semistructured interviews were conducted by C.G. within 3 months after each patient's operation, at a time and place that was convenient to the patient. Interview sites included at the patient's hospital bedside, in a private room at a community library and on the telephone. All interviews were audiotaped and transcribed by C.G.

The interview questions were developed with input from our multidisciplinary team, which included the patient-researcher (M.G.). The questions included:

1. How did you spend your time while you waited for your surgery date?

2. How did you get ready for surgery?

3. What are your thoughts on offering future patients a prehabilitation program, a program that involves interventions (such as, but is not limited to, nutrition, exercise and anxiety-reduction strategies) before surgery with the aim of getting patients in the best possible shape for their operation?

4. Would you have participated in a prehabilitation program if it had been offered?

5. What do you think a prehabilitation program should look like?
The interviewer used prompts and probing as appropriate to elicit more in-depth responses to the questions.

Data collection ceased when saturation was reached. We defined saturation as the point at which code saturation was reached or when no new information was raised by the participants. ${ }^{16}$

\section{Data analysis}

The interview transcripts were coanalyzed by C.G. and M.G. For the purpose of being reflexive and transparent, C.G. is a registered dietitian who has been conducting ERAS and prehabilitation nutrition-related research for more than 10 years. M.G. is a patient with surgery experiences and a trained patient-researcher with the Patient and Community Engagement Research group at the University of Calgary. Our research paradigm aligns with pragmatism: ${ }^{17}$ we believe that the knowledge gained from the patient experience can be used to produce actionable outcomes that support superior health care. C.G. and M.G. analyzed the data independently for the purpose of including multiple perspectives to add breadth to the analysis.

The interviews were analyzed with a reflexive form of inductive thematic analysis. ${ }^{18}$ Coding and theme development were formed from the "bottom-up": that is, codes such as "anxiety" were identified through prioritization of participants' meanings and experiences. We deemed an inductive approach, rather than a deductive approach (i.e., coding data based on predefined codes), appropriate for this work given the paucity of published research on the preoperative experiences of patients in an ERAS setting. The analysis involved 6 steps: 1) familiarization with the data, 2) coding the data based on descriptive elements of the data, 3) identifying potential themes from the codes and sorting data according to identified themes, 4) reviewing and refining the themes (within and across the data set), 5) defining the themes and 6) reviewing the analysis in the context of the current literature. ${ }^{18}$

\section{RESULtS}

Of the 26 patients approached, 6 declined to participate. None of the enrolled participants withdrew from the study. Thus, 20 patients (mean age 62 [standard deviation 13] yr) participated in interviews. Indications for surgery included cancer ( 9 participants [45\%]), benign polyp (2 [10\%]), Crohn disease (4 [20\%]), ulcerative colitis (3 [15\%]) and diverticulitis (2 [10\%]). Twelve participants $(60 \%)$ had attended the presurgery ERAS class.

The interviews were conducted a mean of 25 (standard deviation 13) days after colorectal surgery and lasted 25-60 minutes. Ten interviews were conducted in hospital at the patient's bedside, 6 interviews took place in person after discharge from hospital, and 4 interviews were conducted over the telephone after discharge from hospital. 
We identified 3 main themes from the patient interviews: waiting for surgery (Figure 1), preparing would have been better than just waiting (Figure 2), and partnering with patients (Figure 3).

\section{Waiting for surgery}

Patients described the experience of waiting for surgery as fearful and anxiety-inducing. For patients with cancer (several

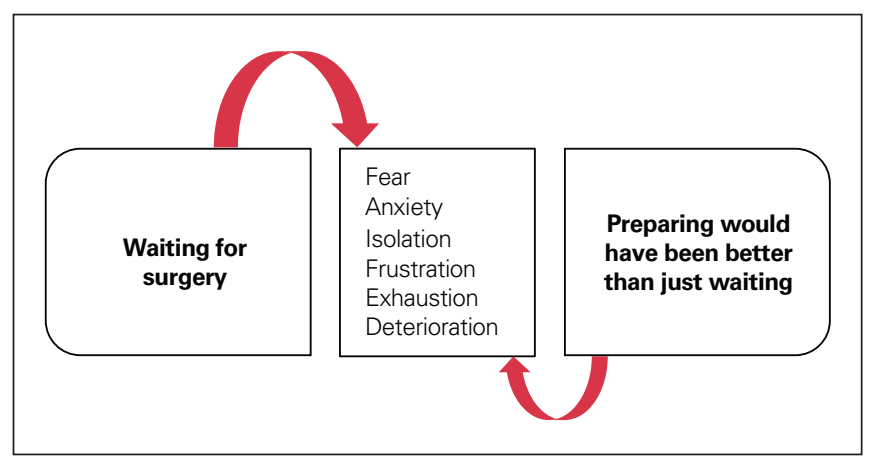

Fig. 1. As participants waited for surgery, they experienced fear, anxiety and isolation, and perceived deterioration of their mental and physical states. Actively engaging patients in the recovery process by preparing for surgery might alleviate some of the anxiety and fear associated with waiting passively for surgery. of whom had had limited health care encounters before their diagnosis), the fear centred around the unknown; an uncertainty as to what was expected of them; and what to expect from their health care providers, their surgical treatment and their cancer outcomes. The fears for the patients without cancer (several of whom were "experienced" patients with multiple health care encounters and, in some cases, prior bowel operations) tended to focus on whether they would require an ostomy, whether recovery would be slow, and whether the surgery would improve their condition (this time):

I was anxious. I was having a nervous breakdown, really, because my life had been turned upside down. I wasn't sure if I was going to die. ... What do I have to do to prepare myself if this is just the end of everything? (70-year-old woman with cancer)

I'm so tired and fed up of thinking I'll have this surgery and everything will be fine afterwards and then you still deal with problems afterwards. ... I know it's a process ... you have to heal and it takes awhile to do it. ... You've been dealing with it for 20 years and you want it done and over with. (64-year-old woman without cancer)

Many patients felt that the period from diagnosis to surgery was isolating and observed little contact from health

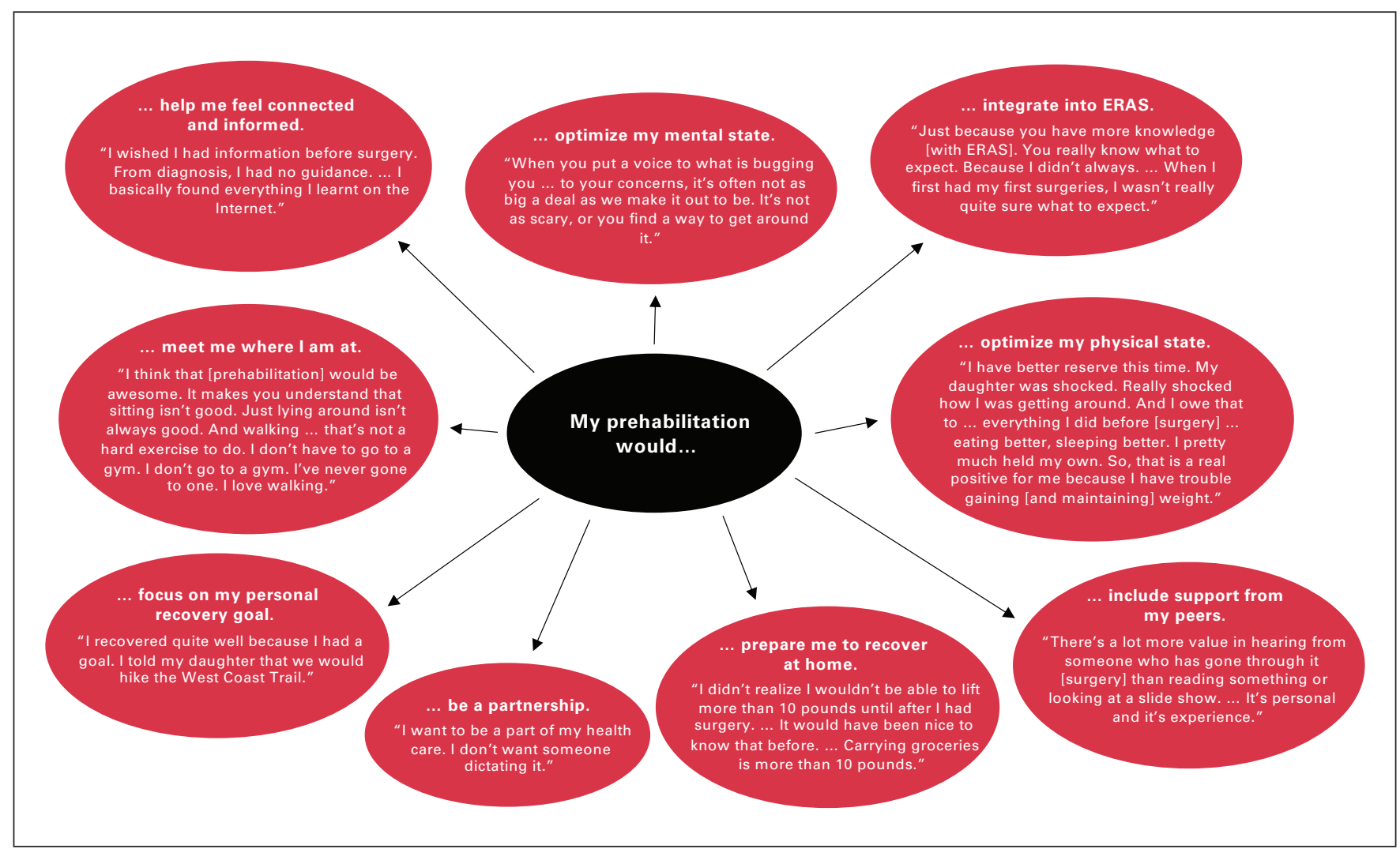

Fig. 2. Patients perceived that a prehabilitation program could prepare them for their operation if it focused on optimizing their mental and physical states, offered personalized support from health care professionals and peers, provided strategies to help get their home and body ready for postoperative recovery, and included surgical expectations (both what to expect and what is expected of them). ERAS = Enhanced Recovery After Surgery. 


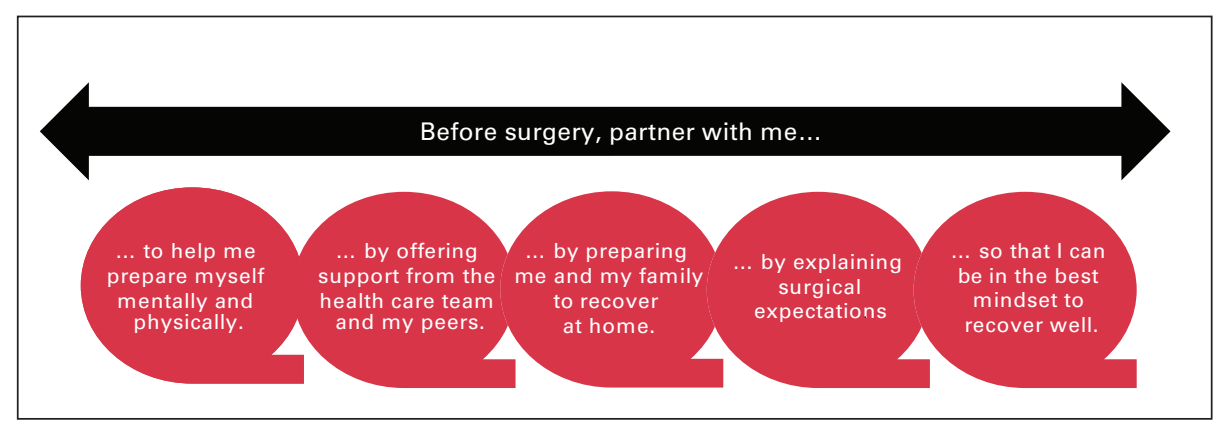

Fig. 3. A patient-oriented preoperative program has the potential to ameliorate deterioration during the waiting period for surgery and promote a mindset to recover well. It is essential to recognize that preoperative preparation should occur on a continuum that meets patients where they are at and in a partnership that respects patients' expertise and desired level of engagement.

care professionals during this time. Many also perceived deterioration of their mental (e.g., anxiety) and physical (e.g., weight loss) states, and the longer they waited for surgery, the greater the deterioration.

What could I do to get ready? ... As far as what to take with you [to the hospital] and that kind of thing that was in the [ERAS] booklet. But for earlier than that, it would have been nice to know things about diet ... to try to get me better ... if there's something I can do ... I'm willing to give it a shot. But I don't know what. ... What can make it better? That's the other thing I'm looking for. (78-year-old man without cancer)

Since before the surgery date, my body started shutting down. I couldn't eat. (39-year-old woman without cancer)

Most patients did not prepare for surgery. In fact, many were unaware of anything they could do to prepare for surgery. Patients expected that their health care providers would inform them how to prepare well for surgery, and since most were not provided with any preparatory advice, many perceived that their role before surgery was to be passive:

I would have to say no [preparation]. ... Most medical professionals over my lifetime have said, "You're in pretty good shape." So ... (84-year-old man without cancer)

Basically, there was no preparation. I just ... I had to come, I had to get it done. (46-year-old man with cancer)

No [preparation], I just sat at home and stressed. (44-year-old woman without cancer)

Interestingly, nearly all of the experienced patients prepared physically for their operation by building a reserve through diet or exercise, or both, or by preparing and freezing meals in anticipation of postsurgical limitations and immobility:
I had a bad experience 13 years ago when I had this [surgery] done. ... So, I said, "If I'm having surgery, I have to be healthy, and I have to have some weight on me." You can't go in there skin and bone ... no reserve. Because it sure didn't work the last time. So, I ate lots and put on a few pounds just to be ready for this, and it's worked ... I'm much stronger. (68-year-old woman without cancer)

If you're fit ... you have an easier recovery afterwards. (64-yearold woman without cancer)

\section{Preparing would have been better than just waiting}

Many patients perceived that a prehabilitation program could prepare them for their operation if it focused on patient-identified priorities: mental preparedness, emotional and social support, understanding surgical expectations (both what to expect and what is expected of them), and having knowledge of postsurgical limitations in order to prepare themselves and their home for postoperative recovery. Patients felt this type of program had the potential to ameliorate the deterioration associated with passively waiting for surgery and "promote a mindset to recover well" (78-year-old woman with cancer).

Patients recognized mental preparedness as vitally important to the success of their surgery and perceived that the greatest strength of a prehabilitation program could be the opportunity to receive additional support (emotional, social and opportunity to address any concerns that might arise). Some patients also saw a prehabilitation program as an opportunity for connection (a "link" to the system) during the perceived void that exists between diagnosis and surgery. Thus, participants identified "outreach" (e.g., follow-up visits and telephone calls) as particularly important as a means to alleviate psychologic stress related to surgery and thus support mental well-being. This was exceptionally important for patients with long surgical wait times (i.e., many patients without cancer): 
They [cancer centre] kept emphasizing positivity and positive attitude. ... I think that has helped me a lot in that recognizing the mind-body connection and recognizing how our experiences, the way we perceive our experiences, is what makes us suffer, not the experience itself ... alone. I can't do anything about it ... I can't undo it. So, I will go forward and make it as easy an experience that I can possibly make it. (70-year-old woman with cancer)

I know it [prehabilitation] costs money ... but ... I wish a program like this was made available to people, so that you had somebody that you could talk to before surgery and somebody that you could go back to after surgery. (44-year-old woman without cancer)

Many patients felt that a prehabilitation team could support them emotionally primarily by listening to them. Several patients expressed a desire to share their fears and concerns with health care professionals and peers:

When you're ... going for surgery ... you're worried about the surgery, worried about how you're going to feel after, worried about [whether you're] going to have a pouch [ostomy] ... what's that all going to look like? I think sharing some of that eases your mind. You go under the anesthetic in a better frame of mind, so you wake up in a better frame of mind. (68-year-old woman without cancer)

If you've never gone through cancer, you've never gone through that fear. ... I can explain it to you, but you haven't gone through it yourself. So, the thing you can do to help me is to hear me. Let me explain my experience to you so that I can feel that you maybe get a little bit of it and I'm not alone. Because if you try to make me feel better or try to make it [fear] go away, then I don't feel heard and I don't feel that you understand. (70-year-old woman with cancer)

In addition, patients identified that the prehabilitation team should include peers with surgery experience. Patient expertise was viewed as critical to alleviate concerns, to help patients prepare well (e.g., 'You don't know if you haven't been through it what questions to ask" [78-year-old woman with cancer]) and to establish buy-in for participation in any program that aimed to get them ready for surgery. However, participants felt that peer support should be regulated to avoid any "horror stories" being told. In addition, participants viewed family as a source of support and felt that their family or caregiver would benefit from participating in prehabilitation as well (e.g., learning what foods to prepare):

I do believe that the deep breathing and whatever else can help. But rather than somebody that's read it in a book telling you, hearing it from someone ... who has experienced it packs a lot more wallop. You know that's not experience, strength and hope ... that's just read out of a book. Just like my experiences the first time [surgery] were helpful and prepped me for this [second surgery]. (68-year-old woman without cancer)
But one thing in the postrecovery ... there should have been a section in there for the spouse or a caregiver as to how to handle people: how to help lift patients out of bed, what signs to watch for trouble and ... what foods would be better than others. ... That kind of thing ... is missing. (78-year-old man without cancer)

Patients expected that a prehabilitation program consisting of exercise and nutrition strategies might help indirectly through preoccupation. Actively engaging patients in their care might alleviate some of the anxiety and fear associated with waiting passively for surgery:

If I'd had some tips ... "Here's some things that you can ... do to not sit at home and stress all day long that something is going to go wrong." ... To have a list of things that I could have done to preoccupy myself. (44-year-old woman without cancer)

I think anything that helps them [patients] to get control is good, and one of the things that we can do is eat properly. (70-year-old woman with cancer)

The few patients who did not perceive exercise prehabilitation to be beneficial understood "exercise" as strenuous or involving gym attendance, which provoked worry related to safety and a possible delay in having their surgery. One patient was convinced that her deteriorating condition could be improved only with surgery, which made the idea of participating in any sort of prehabilitation intervention (e.g., exercise, nutrition) unhelpful. Interestingly, nearly all of these patients opted not to attend the preoperative ERAS education class.

Wouldn't it be wonderful to find yourself getting ready for [your] cancer operation, only to find out you've broken your leg trying to do this [exercise] ... or you've done something ... that screws something ... or your biggest fear: you don't want to come down with a cold, because if you come down with a sickness, your operation is cancelled. I think that's nuts. (77-yearold man with cancer)

No [to prehabilitation]. I wasn't gaining any weight before that surgery, but I've gained about 5 pounds back now. (59-year-old woman without cancer)

Many participants proposed that the best delivery method for a prehabilitation program would be a group class and then additional one-on-one sessions for those who needed or preferred them. Most viewed a class setting as an environment that would enable a relaxed, informal discussion and provide an opportunity for sharing as well as for making peer connections:

Either a group or group meetings for presurgery stuff ... is always going to be helpful. Because there is so much for people to take in. ... If it is done in a group setting where maybe it's a little bit more relaxed and you're generally having a discussion about it, [that] might make it easier. People might take more in 
because you're not directly dealing about me, so I feel more comfortable because you're just talking about it in general. (49-year-old man with cancer)

All participants felt that being well-informed regarding their surgical procedure, expectations and perioperative logistics was of utmost importance to their preoperative education. Nearly every participant praised the preoperative ERAS education group class they had attended for offering clear explanations of what they could expect postoperatively. However, many patients perceived that the ERAS class was missing discharge information that would have helped them better prepare their home and body for recovery. For example, patients wanted to be informed to buy heavy groceries before surgery (given the $4.5-\mathrm{kg}$ weight limit after surgery, which was a surprise for 1 ill-prepared patient), to prepare and freeze appropriate meals before surgery, and to learn how to get out of bed or cough properly with an incision. Patients identified the postoperative period as being too late to receive this information. In addition, some identified the postoperative period as a time when they were inundated with information, which was appreciably more difficult to comprehend at that time given the pain medications:

It was new to me and it was very frightening for awhile. ... When you get explained what is going to happen and how it's going to happen and all the steps to it, it makes you feel so much more comfortable. (71-year-old woman with cancer)

You don't realize what muscles you use to get out of bed. (75-year-old woman without cancer)

\section{Partnering with patients}

Some participants observed that setting realistic and personalized goals was important to their recovery. Prehabilitation programs could be beneficial if structured around partnering with patients to set pre- and postsurgery goals that are relevant to them (e.g., playing hockey again). It is important to meet patients where they are at:

It doesn't have to be exercises; it could just be a walk in nature. ... Do something that makes you feel better. Do something that gives you a little strength, and for each person that will be something different. (70-year-old woman with cancer)

Last, participants expressed a desire to be treated as an expert on their body, and most wanted their expertise recognized in the form of a partnership with their providers. As an example, many experienced patients were aware of what foods aggravated their condition and were frustrated with health care professionals' telling them what foods would or would not bother their digestive tract:
I just couldn't seem to digest things properly, and ... they [health care professionals] told me a little bit of [information]. ... But I also knew the facts with my body, what I was like, what I could eat and tolerate and what I couldn't. (64-year-old woman without cancer)

\section{Discussion}

Our participants identified several preoperative items mental preparedness, emotional and social support, understanding surgical expectations, and having knowledge of postsurgical limitations in order to prepare themselves and their home for postoperative recovery - that they believed improved or could have improved their surgical experience and outcomes. These patient-identified priorities suggest that patient needs can be met through the ERAS element of preoperative education, together with prehabilitation (Table 1). Although prehabilitation focuses largely on patient optimization (mental and physical states) and offers some support, ERAS focuses on surgical expectations and could be modified to include strategies for preparing the home for postoperative recovery (Figure 3). Together, ERAS and prehabilitation might help patients achieve a mindset that permits optimal recovery and perhaps even a sense of agency.

Preoperative patient-related factors, such as anxiety, malnutrition and poor functional capacity, contribute to an exaggerated, prolonged or impaired response to surgical stress, and are associated with adverse outcomes. ${ }^{19,20}$ An aim of multimodal prehabilitation is to work with patients to prepare them metabolically by enhancing cardiorespiratory capacity and physiologic reserves, as well as mentally through antianxiety and coping strategies, to withstand the impending surgical stress response. ${ }^{5}$ Patients who also have surgery under ERAS care benefit from the elements that reduce the metabolic response to surgery, which makes the surgical stress response more tolerable for vulnerable patients. ${ }^{19}$ Collectively, these 2 surgical programs facilitate earlier recovery. ${ }^{21-23}$ The present results add to the literature by highlighting that most patients also perceive prehabilitation integrated within ERAS care to be of personal value.

Surgical recovery has traditionally been viewed as a passive process. In 1989, Baker ${ }^{24}$ conceptualized recovery as a process that moves successively through 3 phases: passivity, activity and stabilization. The author described passivity as a time of rest to support convalescence. She noted that patients progress through these 3 phases by integrating physiologic and health care provider cues with internal and external pressures. Our findings show a similar patient experience. Most of our participants waited for surgery passively because they did not expect that any sort of prehabilitation was necessary, and they relied on their health care providers to inform them of best surgical practices. Yet, nearly all of our participants instinctively agreed that preparing their body for surgery 


\begin{tabular}{|c|c|c|}
\hline Item & Enhanced Recovery After Surgery & Prehabilitation \\
\hline Preoperative optimization & $\begin{array}{l}\text { - Medical clearance for surgery } \\
\text { - Correction of anemia } \\
\text { - Medication management } \\
\text { - Smoking cessation } \\
\text { - Risk stratification and referral to prehabilitation } \\
\text { program }\end{array}$ & $\begin{array}{l}\text { - Nutrition and metabolic optimization, such as } \\
\text { personalized counselling and targeted interventions to } \\
\text { reduce nutrition-impact symptoms (e.g., nausea) and } \\
\text { supplementation to correct malnutrition } \\
\text { - Physical optimization to enhance cardiorespiratory } \\
\text { capacity, build strength, and preserve function through } \\
\text { exercise classes or home exercise programs } \\
\text { - Psychologic preparation and stress reduction, such as } \\
\text { deep-breathing exercises, visualization techniques and } \\
\text { emotional support }\end{array}$ \\
\hline Preoperative patient education & $\begin{array}{l}\text { - Surgical logistics and what patients can expect during } \\
\text { their hospital stay } \\
\text { - Prepare patients to partake in patient-oriented ERAS } \\
\text { elements, including early mobilization } \\
\text { - Answer patient questions during the education } \\
\text { session }\end{array}$ & $\begin{array}{l}\text { - Explain why it is important to prepare for surgery and } \\
\text { how to optimize nutrition, exercise and mental health } \\
\text { before surgery } \\
\text { - Correct misconceptions such as fad diets and that } \\
\text { exercise must involve gym attendance } \\
\text { - Be available to answer questions and offer regular } \\
\text { support (e.g., telephone calls) throughout the } \\
\text { perioperative period }\end{array}$ \\
\hline Additional suggestions from patients & $\begin{array}{l}\text { - Consider offering the preoperative ERAS education as } \\
\text { a group class } \\
\text { - Involve partners and caregivers } \\
\text { - Involve peers with surgery experience } \\
\text { - Discuss postdischarge limitations, such as weight- } \\
\text { lifting restrictions, so that patients can be prepared to } \\
\text { recover well at home (e.g., buying groceries, and } \\
\text { preparing and freezing meals) } \\
\text { - Provide instructions and demonstrations so patients } \\
\text { feel comfortable getting out of bed and coughing after } \\
\text { surgery }\end{array}$ & $\begin{array}{l}\text { - Involve partners and caregivers for additional support } \\
\text { - Cond encouragement } \\
\text { on nutrition or meditation, and exercise classes to } \\
\text { encourage social support } \\
\text { - Include a peer with surgery experience on the team to } \\
\text { reinforce the benefits of nutrition, exercise and } \\
\text { psychologic preparation, as well as augment emotional } \\
\text { support } \\
\text { - Focus on personal recovery goals } \\
\text { - Listen to concerns }\end{array}$ \\
\hline
\end{tabular}

through nutrition, exercise or stress reduction, or some combination of these, would be beneficial once they were presented with the idea. It is clear that prehabilitation constitutes a paradigmatic shift in which recovery is not a passive process, and it begins before surgery. Because this idea challenges long-standing beliefs and traditions, it is unlikely that patients will take the initiative to prehabilitate themselves without direction from their health care providers.

Interestingly, many patients misunderstood "exercise" to be out of their reach given their illness, rather than as personalized movement plans that could be adapted to their unique condition, capabilities and preferences. This misconception is an important finding, as it may affect prehabilitation recruitment rates. It must be addressed in the educational component of prehabilitation, as well as during recruitment to ensure understanding of how movement is beneficial.

Given that many patients reported feelings of isolation in the period from diagnosis to surgery, which they believed could possibly be alleviated with support from a prehabilitation program, establishing supports should be the foundation of prehabilitation programs. In particular, patients identified emotional and social support from peers, family and health care providers to be of value. Social support has been shown to be a significant predictor of health outcomes: a 2010 meta-analysis of 148 studies involving 308849 participants on the extent to which social relationships influence mortality risk indicated a $50 \%$ increased likelihood of survival for participants with stronger social relationships compared to those with weaker social relationships. ${ }^{25}$ Qualitative studies have also shown that supportive care is important for psychologic well-being during the recovery process, ${ }^{26,27}$ and Hodgson and Given ${ }^{28}$ reported that psychologic well-being was a significant factor influencing functional recovery at 4-6 weeks after cancer surgery.

It may be important to consider integrating group classes within existing ERAS and prehabilitation programs. Our participants identified group classes as a possible mechanism to share experiences, hope and strength with their peers and the prehabilitation team. They thought that the prehabilitation team should include a peer with surgery experience to answer their questions, provide insight based on experience (e.g., a list of questions one might want to ask one's surgeon), validate their concerns (i.e., provide emotional reassurance and acceptance) and promote prehabilitative components deemed beneficial based on first-hand experience (e.g., deep breathing for relaxation). Clinical and patient benefits reported in several peer-support studies reinforce the value of this strategy. ${ }^{29-31}$ For example, peer support provided by trained volunteers for adults with diabetes significantly reduced glycated hemoglobin levels relative to usual care. ${ }^{31}$ In addition, a randomized trial of selfmanagement education with or without peer support 
showed that peer-led group sessions with additional telephone support were successful in reducing body mass index and improving cardiovascular risk factors compared to the same program offered without peer support. ${ }^{30} \mathrm{Col}-$ lectively, these findings suggest that, with appropriate support and resources, patients can be empowered agents of change, actively developing their individual expertise to manage their health conditions. ${ }^{32}$

\section{Limitations}

Given that we did not interview patients before surgery and relied on postsurgery accounts of presurgery needs, it is possible that we did not capture the full spectrum of patient experiences and priorities before surgery. In addition, as with all qualitative work, our findings may not be representative of all patients undergoing colorectal surgery. We aimed to recruit a representative sample with our purposive sampling strategy, a common sampling method used in qualitative research; ${ }^{33}$ however, it is possible that this nonprobability sampling strategy introduced bias. In addition, at our site, we already have ERAS group classes in place, which may have encouraged a propensity to favour a class format. Also, our findings suggest that the preoperative needs of patients with cancer and those without cancer differed somewhat (in terms of being experienced $\mathrm{v}$. inexperienced patients and surgical wait times), and this suggests that separate classes tailored to the unique needs of these groups may be appropriate. Our sample size, however, did not allow us to reach saturation to contextualize these group differences. Future studies could aim to explore the unique experiences of these 2 groups.

\section{Conclusion}

Our findings highlight some potential points to consider within prehabilitation programs offered to patients undergoing colorectal surgery. Our patient participants expressed positive feelings about prehabilitation as an addition to ERAS care. For most, waiting passively for surgery was associated with negative feelings and a perceived deterioration in their physical and mental states. Most appreciated the idea of a prehabilitation program directed at addressing their emotional and physical needs, but many had not thought to initiate a prehabilitation program on their own. Participants identified several preoperative items for potential inclusion in ERAS or prehabilitation programs, including emotional and social/ peer support, mental preparedness, and having an available link to the health care team in case of any concerns or questions that arise. They noted the value in having knowledge of surgical expectations and postsurgical limitations so that they, together with their family, could prepare themselves and their home for postoperative recovery. Participants saw the postoperative period as being too late to receive this information. Integrating these patient-identified priorities within ERAS and prehabilitative programs could improve patient satisfaction, experiences and outcomes.

Affiliations: From the Department of Community Health Sciences, Cumming School of Medicine, University of Calgary, Calgary, Alta. (Gillis); the Patient and Community Engagement Research program, University of Calgary, Calgary, Alta. (Gill); the Department of Medicine, University of Alberta, Edmonton, Alta. (Gramlich); the Faculty of Kinesiology, University of Calgary, Calgary, Alta. (Culos-Reed); the Departments of Oncology and of Obstetrics and Gynaecology, Cumming School of Medicine, University of Calgary, Calgary, Alta. (Nelson); the Department of Surgery, School of Health and Medical Sciences, Faculty of Medicine and Health, Örebro University, Örebro, Sweden (Ljungqvist); the Department of Anesthesia, McGill University Health Centre, Montréal, Que. (Carli); and the Department of Community Health Sciences, Institute of Public Health, Alberta Children's Hospital Research Institute, Calgary, Alta. (Fenton).

Competing interests: Gregg Nelson is secretary of the ERAS Society. He reports consulting fees from Abbott Laboratories and speaker fees from Medtronic, outside the submitted work. Olle Ljungqvist is chairman of the ERAS Society. He founded and owns stock in Encare and has received honoraria, including travel support, for advice and lecturing from Nutricia, Fresenius Kabi, Pharmacosmos and Encare, and lecturing honoraria from Medtronic and B. Braun, outside the submitted work. No other competing interests were declared.

Contributors: C. Gillis, M. Gill, L. Gramlich, N. Culos-Reed. O. Ljungqvist, F. Carli and T. Fenton designed the study. C. Gillis and M. Gill acquired and analyzed the data. C. Gillis wrote the manuscript, which M. Gill, L. Gramlich, N. Culos-Reed, G. Nelson, O. Ljungqvist, F. Carli and T. Fenton critically revised. All authors gave final approval of the article to be published.

Content licence: This is an Open Access article distributed in accordance with the terms of the Creative Commons Attribution (CC BYNC-ND 4.0) licence, which permits use, distribution and reproduction in any medium, provided that the original publication is properly cited, the use is noncommercial (i.e., research or educational use), and no modifications or adaptations are made. See: https://creativecommons. org/licenses/by-nc-nd/4.0/.

Funding: This study was supported by Canadian Institutes of Health Research Strategy for Patient-Oriented Research (SPOR) Collaboration Grant PEG-151772 to Leah Gramlich. Funding for Chelsia Gillis was provided by a Vanier Canada Graduate Scholarship.

\section{References}

1. Gustafsson UO, Scott MJ, Hubner M, et al. Guidelines for perioperative care in elective colorectal surgery: Enhanced Recovery After Surgery (ERAS®) Society recommendations: 2018. World 7 Surg 2019;43:659-95.

2. Ljungqvist O, Scott M, Fearon KC. Enhanced Recovery After Surgery: a review. FAMA Surg 2017;152:292-8.

3. Nelson G, Kiyang LN, Crumley ET, et al. Implementation of Enhanced Recovery After Surgery (ERAS) across a provincial healthcare system: the ERAS Alberta colorectal surgery experience. World $\mathcal{F}$ Surg 2016;40:1092-103.

4. Carli F. Physiologic considerations of Enhanced Recovery After Surgery (ERAS) programs: implications of the stress response. Can 7 Anaesth 2015;62:110-9.

5. Carli F, Gillis C, Scheede-Bergdahl C. Promoting a culture of prehabilitation for the surgical cancer patient. Acta Oncol 2017;56:128-33.

6. Santa Mina D, Clarke H, Ritvo P, et al. Effect of total-body prehabilitation on postoperative outcomes: a systematic review and meta-analysis. Physiotberapy 2014;100:196-207. 
7. Gillis C, Li C, Lee L, et al. Prehabilitation versus rehabilitation: a randomized control trial in patients undergoing colorectal resection for cancer. Anesthesiology 2014;121:937-47.

8. Yun PS, MacDonald CL, Orne J, et al. A novel surgical patient engagement model: a qualitative study of postoperative patients. $\mathcal{F}$ Surg Res 2020;248:82-9.

9. Canada's Strategy for Patient-Oriented Research: improving health outcomes through evidence-informed care. Ottawa: Canadian Institutes of Health Research; 2011.

10. Coulter A. Patient engagement - What works? f Ambul Care Manage 2012;35:80-9.

11. Crowe S, Fenton M, Hall M, et al. Patients', clinicians' and the research communities' priorities for treatment research: there is an important mismatch. Res Involv Engagem 2015;1:2.

12. Bagley HJ, Short H, Harman NL, et al. A patient and public involvement (PPI) toolkit for meaningful and flexible involvement in clinical trials - a work in progress. Res Involv Engagem 2016;2:15.

13. Domecq Garces JP, Prutsky Lopez GJ, Wang Z, et al. Eliciting patient perspective in patient-centered outcomes research: a meta narrative systematic review. Rochester (MN): Patient-Centered Outcomes Research Institute; 2012.

14. Sibbern T, Bull Sellevold V, Steindal SA, et al. Patients' experiences of enhanced recovery after surgery: a systematic review of qualitative studies. 7 Clin Nurs 2017;26:1172-88.

15. Gillis C, Gill M, Marlett N, et al. Patients as partners in Enhanced Recovery After Surgery: a qualitative patient-led study. BMJ Open 2017;7:e017002.

16. Hennink MM, Kaiser BN, Marconi VC. Code saturation versus meaning saturation: How many interviews are enough? Qual Health Res 2017;27:591-608.

17. Kaushik V, Walsh CA. Pragmatism as a research paradigm and its implications for social work research. Soc Sci 2019;8:255.

18. Braun V, Clarke V. Reflecting on reflexive thematic analysis. Qual Res Sport Exerc Health 2019;11:589-97.

19. Soeters PB, Grimble RF. Dangers, and benefits of the cytokine mediated response to injury and infection. Clin Nutr 2009;28:583-96.

20. Fearon KC, Ljungqvist O, Von Meyenfeldt M, et al. Enhanced Recovery After Surgery: a consensus review of clinical care for patients undergoing colonic resection. Clin Nutr 2005;24:466-77.
21. Lau CS, Chamberlain RS. Enhanced Recovery After Surgery programs improve patient outcomes and recovery: a meta-analysis. World F Surg 2017;41:899-913.

22. Gillis C, Buhler K, Bresee L, et al. Effects of nutritional prehabilitation, with and without exercise, on outcomes of patients who undergo colorectal surgery: a systematic review and meta-analysis. Gastroenterology 2018;155:391-410.e4.

23. Tsimopoulou I, Pasquali S, Howard R, et al. Psychological prehabilitation before cancer surgery: a systematic review. Ann Surg Oncol 2015;22:4117-23.

24. Baker CA. Recovery: a phenomenon extending beyond discharge. Sch Inq Nurs Pract 1989;3:181-94, discussion 195-7.

25. Holt-Lunstad J, Smith TB, Layton JB. Social relationships and mortality risk: a meta-analytic review. PLoS Med 2010;7:e1000316.

26. Baker CA. Reflections on "recovery: a phenomenon extending beyond discharge." Sch Inq Nurs Pract 2001;15:83-8.

27. Nilsson U, Unosson M, Kihlgren M. Experience of postoperative recovery before discharge: patients' views. 7 Adv Perioper Care 2006; 2:97-106.

28. Hodgson NA, Given CW. Determinants of functional recovery in older adults surgically treated for cancer. Cancer Nurs 2004;27: 10-6.

29. Chan JC, Sui Y, Oldenburg B, et al. Effects of telephone-based peer support in patients with type 2 diabetes mellitus receiving integrated care: a randomized clinical trial. 7 AMA Intern Med 2014; 174:972-81.

30. Tang TS, Funnell MM, Sinco B, et al. Peer-Led, EmpowermentBased Approach to Self-Management Efforts in Diabetes (PLEASED): a randomized controlled trial in an African American community. Ann Fam Med 2015;13(Suppl 1):S27-35.

31. Ayala GX, Ibarra L, Cherrington AL, et al. Puentes hacia una mejor vida (Bridges to a Better Life): outcome of a diabetes control peer support intervention. Ann Fam Med 2015;13(Suppl 1):S9-17.

32. Hunter J, Franken M, Balmer D. Constructions of patient agency in healthcare settings: textual and patient perspectives. Discourse Context Media 2015;7:37-44.

33. Palinkas LA, Horwitz SM, Green CA, et al. Purposeful sampling for qualitative data collection and analysis in mixed method implementation research. Adm Policy Ment Health 2015;42:533-44. 